\title{
Development and research of vacuum-plasma composite coatings for increase of operability of shearing dies
}

\author{
Marina A. Volosova ${ }^{1}$, Anton E. Seleznev ${ }^{1}$, Alexander A. Shein ${ }^{1}$ \\ ${ }^{1}$ Moscow State University of Technology "STANKIN",1 Vadkovskiy per., Moscow, 127055, Russia Federation
}

\begin{abstract}
The technological principles of low-temperature deposition of multilayer vacuum-plasma coatings with the increased operational properties on various types of die steels with the assistance of accelerated argon molecules beam are offered in the article. Four standard architecture of vacuum-plasma coatings - Ti/(Ti, Zr)N, Cr/CrN, TiN/TiCN/(Ti, Cr)N and $\mathrm{Ti} /(\mathrm{Ti}, \mathrm{Al}) \mathrm{N}$ are considered. It is shown that deposition of vacuum-plasma coatings of the listed structures at the optimum modes considerably reduces intensity of wear of shearing dies therefore quality of shaped products several times increases.
\end{abstract}

Keywords: dies, wear, cutting-out, low-carbon steel, aluminum alloy, corrosion-resistant steel, carbon steel.

\section{Introduction}

The practice shows that the intensive wear of the working surfaces of the shearing dies substantially reduces indicators of quality of the stamped parts, increases the resistance to separation up to $20 \%$, and the total work of separation up to $40 \%$ compared with the operation activity of the tool with sharp cutting edges. The common industrial method of reducing the wear rate of metal-working tools is the application of different coatings of the working surfaces $[1,2,3]$. In forging production the coating technologies do not have wide application, primarily due to the complicated dynamic loads imposed on the working surfaces of tools in the process of stamping, which makes inefficient the use of coatings, traditional for other metalworking areas, such as TiN, TiCN, and others.

\section{Features of the wear of shearing dies and functions of the coatings}

Depending on technological conditions of the shearing stamp process and on operating loads, there may be different fracture mechanisms and failure modes of the punch and the die - adhesive and abrasive wear, chipping of the work surfaces, tempering of a thin surface layer and an intense pickup of deformable material on the operating surface of the tool $[4,5]$.

The analysis of the results of experimental research shows that, depending on the conditions of the shearing stamp process wear resistant coatings applied on the working surface of the tool should perform the functions of:

- highly rigid surface layer that prevents abrasive wear of the working surfaces of the tool in the stamping process;

- intermediate agent with a deformable material that prevents intense grabbing in terms of adhesive wear;
- anti-friction solid lubricant, minimizing the pickup of a deformable material on the tool in the stamping process;

- barrier layer that prevents the temper of the surface layer of the tool as a result of exposure of elevated thermal loads;

- barrier layer, that is able to inhibit or stop the spread of the grid of fatigue cracks, leading to macrochipping of the working edges.

\section{Technology of application of vacuum-plasma coatings on the shearing dies}

As the work items of the shearing dies depending on seriation and other conditions of production organization are made of hot-short $\left(220-250{ }^{\circ} \mathrm{C}\right)$ steals of the types C105W1, 105WCr6 (DIN) and semi-heatproof (490-510 $\left.{ }^{\circ} \mathrm{C}\right)$ tool steels of the types X165CrMoV12 and K190PM (DIN), applying the traditional techniques of high-temperature vacuum-plasma coating is impractical. Even a slight rise of the temperature of coating relative to the level of acceptable heat resistance of the tool material, inevitably leads to tempering of working edges and loss of operability of the tool. At the same time, insufficient cleaning and activation of the surface often leads to delamination of the coatings in the first minutes of tool work, which is a consequence of low strength of the adhesive bond of the coating with the surfaces of the tool.

To solve the problem of temperature reduction in the process of applying of vacuum plasma coatings on die steels, was used an innovative device developed in MSTU "STANKIN", that generates a beam of accelerated neutral molecules of different gases (e.g. argon) that provide the desired heating and cleaning of the surface at the expense of its kinetic energy [6]. In this case, even with a 
significant decline in the value of the negative potential or even without it, it's possible to provide the necessary cleaning and activation of the surface. The heating temperature of the surface of the samples does not exceed $180{ }^{\circ} \mathrm{C}$, that ensures the ability of continuous etching of the surface of the substrate without tempering or warpage of the working edge of the tool.

The plasma, consisting of neutral molecules of different gases, uniformly distributes over the surface of a tool of any geometrical shape and provides uniform cleaning within the line of sight of all complex-shaped surfaces.

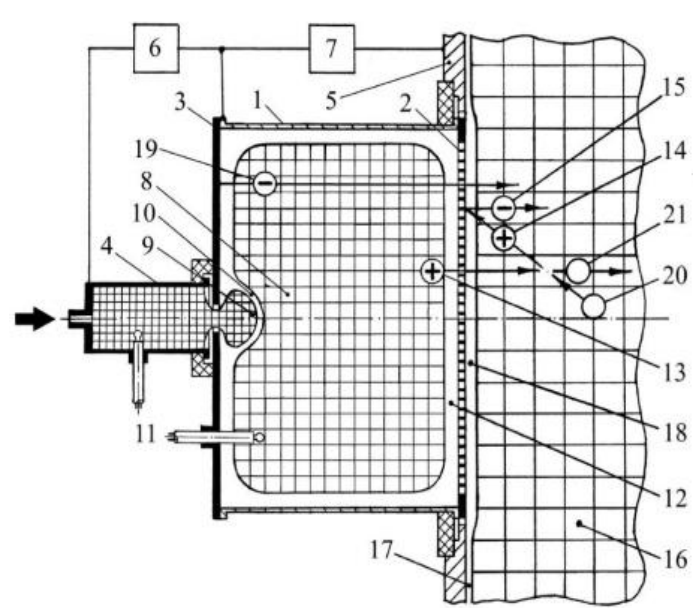

Figure 1. The design of the source of fast neutral molecules beam.

Fig. 1 demonstrates a scheme of the device. It comprises a cylindrical hollow cathode 1 with a diameter of $12 \mathrm{~cm}$ and length $8 \mathrm{~cm}$, covered on one side with a grid 2 in the form of a disc $2 \mathrm{~mm}$ thick with 1224 holes with a diameter of $2 \mathrm{~mm}$, and on the other side with the disk 3 with a central hole with a diameter of $8 \mathrm{~mm}$.

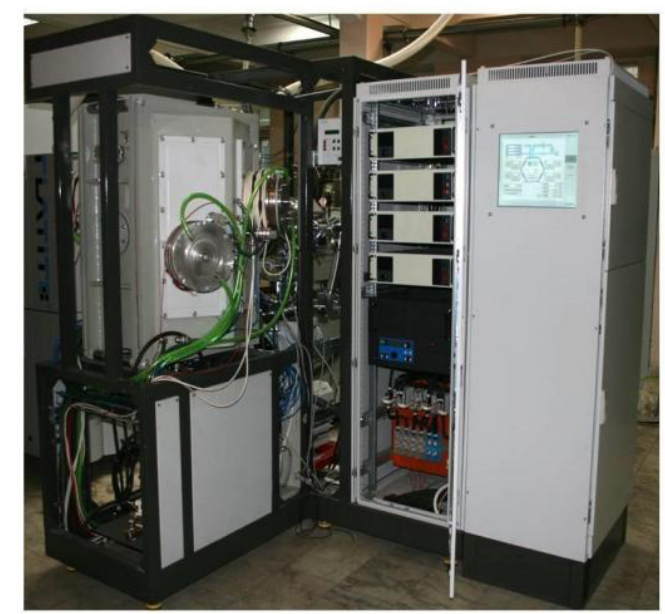

Figure 2. The experimental unit for applying wear-resistant coatings on the tool.

Through this hole the cathode cavity communicates with a hollow anode 4 with a diameter of $2 \mathrm{~cm}$ and a length of $4 \mathrm{~mm}$. Hollow cathode 1 is installed in the center of the end flange 5 of the vacuum chamber with a diameter of 26 $\mathrm{cm}$ and a length of $30 \mathrm{~cm}$, pumped by a diffusion pump with liquid nitrogen trap. The gas is fed into the hollow anode 4 , through a hole with a diameter of $8 \mathrm{~mm}$, it flows into the hollow cathode 1 and then through the cathode grid 2 is fed into the vacuum chamber. At a sufficient flow rate of the gas the pressure inside the hollow anode 4 exceeds the pressure in hollow cathode 1 and the camera by a decade. Cathode 1 , anode 4 and the chamber are made of non-magnetic stainless steel and are insulated from each other.

The discharge between the anode and the cathode is supported by the rectifier 6 with a voltage of $1.5 \mathrm{kV}$ and the source 7 allows to change the potential of the cathode $\varphi$ relative to the camera from $1 \mathrm{kV}$ to $+1 \mathrm{kV}$. Two solenoids, covering the end flanges of the camera, create axial magnetic field with intensity up to 500 Oe, homogeneous throughout the volume of the hollow cathode and chamber, and an optical window in the center of the opposite flange of the camera allows to see the glow of the discharge inside the cathode through the grid.

At the ignition of the discharge, the cathode 1 is filled with sufficiently uniform glow of plasma 8 , and in its central hole there is a brighter glow of the anode plasma 9 of double electrostatic layer 10 that penetrates into the cathode 1 from the hollow anode 4.

A part of ions 13 accelerated in the layer 12 penetrate into the chamber through the holes of the grid 2, and this leads to an increase of the potential of the space inside it. As a result of interaction of ions 13 and 14 with the chamber walls and the grid 2 appear secondary electrons 15. They are captured in an electrostatic trap of the space charge of the ions and compensate this charge, making multiple oscillations in the trap. Occurs the synthesis of the quasi-neutral plasma 16 separated from the chamber wall 5 by a layer of positive space charge 17 .

On the base of the study of properties of existing promising thin-film coatings and experience in their use, were offered four different variants of wear-resistant coatings that enhance the operability of the working elements of the shear dies and the quality of fabricated parts for various character of existing loads and wear mechanisms:

1) $\mathrm{Ti} /(\mathrm{Ti}, \mathrm{Zr}) \mathrm{N}$ coating - enhances the operability of the tool in the simultaneous occurrence of adhesive and abrasive wear. The outer layer of nitride (Ti,Zr)N increases the microhardness of the working surfaces of the tool (up to $28 \mathrm{hPA}$ ) and has a high resistance to molecular grabbing with the majority of processed materials. The introduction of a sublayer of titanium enhances the strength of the adhesive bond between the outer layer and the instrumental material by reducing the difference of their physical, mechanical and thermal properties, leading to the formation of large residual stresses in the coating.

2) $\mathrm{Cr} / \mathrm{CrN}$ coating - enhances the performance of the tool in terms of adhesion wear and intense pickup of workpiece material on the working surface of the tool. The outer layer based on nitride $\mathrm{CrN}$ simultaneously increases anti-friction properties (decreasing coefficient of friction in 2 times) and increases the microhardness of the working surfaces of the tool up to $14 \mathrm{hPA}$.

3) $\mathrm{TiN} / \mathrm{TiCN} /(\mathrm{Ti}, \mathrm{Cr}) \mathrm{N}$ coating - enhances the operability of the tool in terms of brittle fracture (chipping) of working edges and abrasive wear. This coating 
effectively inhibits the development of cracks as it consists of three alternating layers of variable hardness, significantly increases the cracking resistance and fracture toughness of the composition "coating-tool". The outer coating layer consisting of a nitride $(\mathrm{Ti}, \mathrm{Cr}) \mathrm{N}$, increases the microhardness of the working surfaces of the tool up to 24 hPA.

4) $\mathrm{Ti} /(\mathrm{Ti}, \mathrm{Al}) \mathrm{N}$ coating - enhances the operability of the tool in terms of frequent overheating of cutting edges and/or intensive abrasive wear. A distinctive feature of nitride $(\mathrm{Ti}, \mathrm{Al}) \mathrm{N}$ in addition to its increased microhardness (up to $37 \mathrm{hPA}$ ) is a high temperature resistance and the formation on the surface of a dense amorphous A12O3 layer during heating, that serves as a kind of thermal barrier that protects the surface layers of the tool from the effects of thermal stress, which often occurs during the pressing of corrosion resistant steels and other hard materials.

\section{Research of operability of the shearing dies with various vacuum-plasma coatings}

The experiments simulated the different wear mechanisms, typical for the real operating conditions of the shearing dies. For this purpose were made four groups of punches and dies of different shapes and sizes made of steel X165CrMoV12, which in accordance with the developed technological principles were coated with vacuum-plasma coatings of different composition.

The tests of punching tools with coatings applied at different technological modes were carried out at cutting and punching of products of various sizes:

- coating $\mathrm{Ti} /(\mathrm{Ti}, \mathrm{Zr}) \mathrm{N}$ - when punching holes in low-carbon steel DC04G1 (DIN) $4 \mathrm{~mm}$ thick in the simultaneous occurrence of adhesive and abrasive wear;

- coating $\mathrm{Cr} / \mathrm{CrN}$ - when cutting the outer contour of parts ("leverage" type) in aluminum alloy G-AlMg5 (DIN) $4 \mathrm{~mm}$ thick in the conditions of adhesion of intensive wear and pickup of the material of the workpiece on the working surface of the tool;

- coating in $\mathrm{TiN} / \mathrm{TiCN} /(\mathrm{Ti}, \mathrm{Cr}) \mathrm{N}$ - when punching the outer contour of parts ("star" type) in high-carbon steel C $80 \mathrm{~W} 2$ (DIN) $4 \mathrm{~mm}$ thick in terms of heavy chipping and abrasive wear of the working surfaces of the tool;

- coating in $\mathrm{Ti} /(\mathrm{Ti}, \mathrm{Al}) \mathrm{N}$ - when cutting holes in corrosion-resistant steel X10CrNiTi18-9 (DIN) $4 \mathrm{~mm}$ thick in terms of frequent overheating and, as a consequence, tempering of working edges.

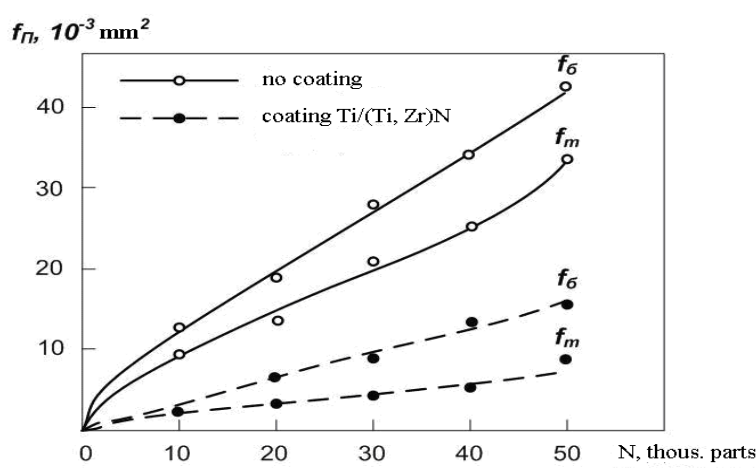

Figure 3. The dependence of the butt $f_{m}$ and side $f_{\sigma}$ wear of the punch when punching holes in the material DC04G1 on the number of stamped details.

Fig. 3 shows fragments of experimental studies of dependence of the wear of the punch with different coatings on the number of stamped parts made of steel DC04G1. The results of experiments conducted on the samples of aluminum alloy G-AlMg5, which has the most intense burr-formation, also showed a significant effect from the use of proposed coatings.

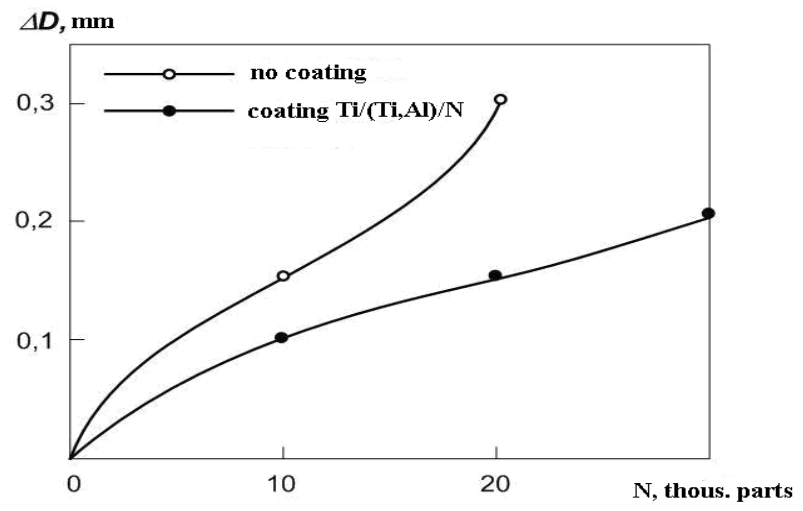

Figure 4. The dependence of size of the holes in the material X10CrNiTi18-9 on the number.

Fig. 4 shows the change of the size of the hole, punched in steel X10CrNiTi18-9, depending on the number of stamped parts. It is noticeable that at the time of punching of 20 thousand holes, the application of the proposed coating allows to halve the deviation of the size of the hole.

\section{Conclusion}

To ensure the ability of the application of high quality coatings on hot-short steels and semi-heatproof shear die steels can be used the proposed technological principles of low-temperature deposition of multilayer vacuum-plasma coatings in the mode of assisting with the beam of accelerated molecules of argon. It is proposed to use four typical variants of architecture of vacuum-plasma coatings - Ti/(Ti,Zr)N, Cr/CrN, TiN/TiCN/(Ti,Cr)N and $\mathrm{Ti} /(\mathrm{Ti}, \mathrm{Al}) \mathrm{N}$.

On the basis of processing of the results of operational tests was established the fact that the application of a vacuum plasma coating under optimal conditions reduces the wear rate of the shearing dies more than in 2.5 times; 
the height of the burr formed on the end butt of the surface of the parts reduces in 3 times, and the deviation of the sizes of the parts in 2 times.

The work is performed with financial support of the Russian Science Foundation within the Agreement No. 14-29-00297 of August 6, 2014.

The work is carried out on the equipment of the Center of collective use of MSTU "STANKIN" with financial support of the Ministry of Education and Science of Russian Federation, the Agreement No. 14.593.21.0004 of 04.12.2014, the unique identifier of the project RFMEFI59314X0004.

\section{References}

1. S.N. Grigoriev, M.A. Volosova, Complex surface hardening of oxide-carbide ceramic cutting tools, Rus. Eng. Res. 9 (2005) 7-12.

2. A.A. Andreev, I.V. Serdyuk, V.M. Beresnev, M.A. Volosova, S.N. Grigoriev, D.A. Kolesnikov, A.D. Pogrebnyak, O.V. Sobol, P.V Turbin, Tribological characteristics of nanocomposite vacuum-plasma TI-HF, TI-HF-N, and TI-HF-SI-N coatings, J. of Frict. and Wear. Vol. 34.

3

(2013)

175-182.
3. A.S. Vereschaka, S.N. Grigoriev, E.S. Sotova, A.A. Vereschaka, V.P. Tabakov, M.Yu. Kulikov, Improving the efficiency of the cutting tool made of ceramic when machining hardened steel by applying nano-dispersed multi-layered coatings. Key Eng. Mat. Vol. 581 (2014) $68-73$.

4. S.N. Grigoriev, Yu.A. Melnik, A.C. Metel, Broad fast neutral molecule beam sources for industrial-scale beam-assisted deposition, Surf. and Coat. Tech. Vol. 156 №1-3 (2002) 44-49.

5. A.S. Vereschaka, S.N. Grigoriev, E.S. Sotova, A.A. Vereschaka, Improving the efficiency of the cutting tools made of mixed ceramics by applying modifying nano-scale multilayered coatings, Adv. Mat. Res. Vol. 712-715 (2013) 391-394.

6. A.C. Metel, V.P. Bolbukov, M.A. Volosova, S.N. Grigoriev, Yu.A. Melnik, Source of metal atoms and fast gas molecules for coating deposition on complex shaped dielectric products, Surf. and Coat. Tech. Vol. 225 (2013) 34-39. 